\title{
Xanthan Lyases - Novel Enzymes Found in Various Bacterial Species
}

\author{
By IAN W. SUTHERLAND \\ Department of Microbiology, Edinburgh University, West Mains Road, Edinburgh EH9 3JG, UK
}

(Received 18 May 1987)

\begin{abstract}
Xanthan lyases, cleaving the terminal $\beta$-mannosidic linkage of the side-chain of the exopolysaccharide xanthan from Xanthomonas campestris, have been obtained from several sources. These include a Bacillus species, a Corynebacterium species and a mixed culture. The lyases were initially associated with endo- $\beta$-glucanases cleaving the main chain of xanthan. Partial purification of the enzymes was achieved and the Bacillus preparation was separated by FPLC into material free of endoglucanase and glycosidase activities. The lyase was active on polysaccharides with and without acetate and pyruvate. The optimal size of the substrate appeared to be in the range of degree of polymerization (DP) 25-35, i.e. 5-7 repeat units of the polysaccharide. No activity was found against xanthan modified by reduction of the carboxyl groups or by the addition of amine or hydroxyethyl groups. The combined action of the lyase and the endoglucanase yielded a series of oligosaccharides, each with a side-chain terminating in an unsaturated uronic acid and containing the molar ratio of D-glucose to D-mannose, 2:1.
\end{abstract}

\section{INTRODUCTION}

Lyases, enzymes generating unsaturated uronic acid residues in the breakage of polysaccharide chains, have been recognized for various bacterial exopolysaccharides (EPS). Thus, alginate lyases have been isolated from a number of bacterial species as well as from marine invertebrates. These enzymes differ in their specificity, some being poly- $\alpha$-L-guluronate lyases (Davidson et al., 1976; Boyd \& Turvey, 1977), while others are poly- $\beta$-D-mannuronate lyases (Davidson et al., 1977; Currie \& Turvey, 1982). Similarly, hyaluronate lyases acting on the polymer synthesized by Streptococcus species and enzymes with similar action for various bacterial EPS have been identified. These include some from heterologous bacteria and others from bacteriophage. In all the polymers cleaved by such lyases, the uronic acid residues are present in the main chain of linear molecules. Bacterial EPS containing uronic acids are of frequent occurrence, the charged carbohydrate residues either forming part of the main chain or being side-chain components.

Xanthan, the EPS from Xanthomonas campestris strains, contains one molecule of Dglucuronic acid as the subterminal residue of a trisaccharide side-chain attached to cellobiose as a pentasaccharide repeat unit (Jansson et al., 1975; Melton et al., 1976). A number of hydrolytic enzymes degrading xanthan have been identified, mainly endo- $\beta$-glucanases cleaving the cellulosic main chain (Holt, 1978; Sutherland, 1982; Hou et al., 1986). Under certain restricted conditions, fungal cellulases will also hydrolyse xanthan (Rinaudo \& Milas, 1980; Sutherland, 1984). A mixed culture containing enzymes cleaving the side-chain sugars and leaving the cellulosic main chain of xanthan intact has also been reported (Cadmus et al., 1982).

In an early study on enzymic degradation of xanthan, Lesley (1961) reported the presence of unsaturated oligosaccharides among the products; Holt (1978) also indicated that the fragments generated by enzymes from a Corynebacterium species showed absorption at $235 \mathrm{~nm}$ indicative of the action of a lyase. The present study reports the preparation, partial purification and some

Abbreviations: DP, degree of polymerization; EPS, exopolysaccharide(s); TBA, thiobarbituric acid. 
properties of a xanthan lyase from a Bacillus strain earlier found to secrete an endo- $\beta$-glucanase and a $\beta$-D-glucosidase (Sutherland, 1982), and its comparison with similar enzymes from other isolates.

\section{METHODS}

Bacteria and culture conditions. The three bacterial systems used were a Bacillus species described earlier (Sutherland, 1982); a Corynebacterium species (Holt, 1978); and a mixed culture (X23) isolated by enrichment, which contained a yellow-pigmented Gram-negative rod as the dominant micro-organism. Enzymes were only produced in significant yield in the mixture. All cultures grew in synthetic medium containing $0.1 \%(\mathrm{w} / \mathrm{v})$ xanthan as the carbon source (Sutherland, 1982). After approximately $6 \mathrm{~d}$ incubation in shaken 2-litre Erlenmeyer flasks at $30{ }^{\circ} \mathrm{C}$, the cells were removed by centrifugation at $50000 \mathrm{~g}$. The supernatant fluids containing endo- $\beta$-glucanase, lyase and other enzymes were concentrated in a tangential-flow filtration cell (Waters) using a non-cellulosic membrane system with $10000 M_{\mathrm{r}}$ cut-off. The final concentrated solution (about $300 \mathrm{ml}$ from 101 supernatant

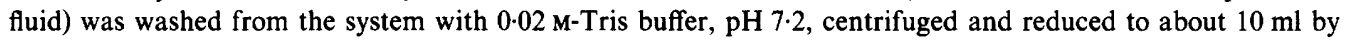
dialysis against polyethylene glycol $\left(M_{\mathrm{r}} 6000\right)$. This was used as the starting material for studies of the xanthan lyases. Preparations from each source showed similar activity, but differed in their content of glucosidases and mannosidases. No endoglucanase or lyase activities were detectable in either the pure or mixed cultures grown in the absence of xanthan, indicating that all the systems were inducible.

Enzyme assays. Substrates were xanthan polysaccharides obtained from commercial producers or prepared from different $X$. campestris pathovars in our laboratory. Some were chemically modified by deacetylation, depyruvylation, addition of amine groups, or reduction of the carboxyl groups (Bradshaw et al., 1983). Polysaccharides from Acetobacter xylinum strains were kindly supplied by $\mathrm{Dr}$ E. Weng and Dr A. Misaki. Lyases were assayed by determination of thiobarbituric acid (TBA) positive material (Weissbach \& Hurwitz, 1958). The presence of glycosidase activities in enzyme preparations was determined using $p$-nitrophenyl D-glucopyranosides and D-mannopyranosides. Cellulase (endo- $\beta$-glucanase) activity was confirmed using carboxymethylcellulose as substrate in a Brookfield LVT cone-plate viscometer at $30^{\circ} \mathrm{C}$. Neutral sugars in hydrolysates of the polysaccharides or oligosaccharides were determined by HPLC using the procedure outlined by Kennedy \& Sutherland (1987). Hydrolysis was with $0.25 \mathrm{M}-\mathrm{H}_{2} \mathrm{SO}_{4}$ at $100{ }^{\circ} \mathrm{C}$ for $8 \mathrm{~h}$. Acyl groups in intact polysaccharides and oligosaccharides and uronic acid were determined by micromethods described previously (Sutherland, 1984). Xanthan fragments of varying size prepared by cellulase hydrolysis (Sutherland, 1984) and those from the combined action of lyases and endoglucanases were separated on a Biogel P2 column $(56 \times 1 \mathrm{~cm})$ using water as eluant at a flow rate of $0.6 \mathrm{ml} \mathrm{min}{ }^{-1}$, and by paper chromatography in ethyl acetate/acetic acid/formic acid/water $(18: 3: 1: 4$, by vol.).

FPLC. Concentrated eluates from fractionation on DEAE-Sepharose were applied to an Ultropac TSK 545 DEAE ion-exchange column $(150 \times 7.5 \mathrm{~mm})(\mathrm{LKB})$ and eluted with a complex salt gradient in $50 \mathrm{mM}$-HEPES buffer, $\mathrm{pH} 7 \cdot 6$, using a Gilson system. Protein was determined by the Lowry procedure.

NMR spectroscopy. NMR spectroscopy and FAB spectroscopy were kindly carried out by Dr L. Parolis (Rhodes University, Grahamstown, S. Africa) and Dr A. J. Clarke-Sturman (Shell Research, Sittingbourne, UK) respectively.

\section{RESULTS}

\section{Production and purification of xanthan lyases}

Enrichment cultures in our laboratory yielded a number of mixed bacterial cultures which, when grown in media with xanthan as sole carbon source, produced enzymes degrading the polysaccharide. Supernatant fluids from such cultures caused loss of viscosity of xanthan and carboxymethylcellulose solutions and the liberation of TBA-positive material from the former. It was further seen that absorption at $235 \mathrm{~nm}$ increased, indicative of release of fragments containing unsaturated uronic acids. In most cases, attempts to obtain pure cultures with comparable activities were unsuccessful. However, an earlier study (Sutherland, 1982) yielded a red-pigmented Bacillus species which grew in xanthan-containing media, produced extracellular enzymes with endoglucanase and glycosidase activities, and released fragments which were TBA-positive. Similar enzymes and products were found using the Corynebacterium supernatants and those from mixture X23. The endoglucanase (xanthanase) and lyase activities from each preparation could be partially purified by chromatography on DEAE-Sepharose. This removed most of the $\alpha$ - and $\beta$-D-glucosidase and $\alpha$ - and $\beta$-D-mannosidase activities. The material from either of the two pure cultures could be purified further by FPLC. Monitoring of the eluate at $280 \mathrm{~nm}$ indicated that two major components were separated (Fig. 1); these were 


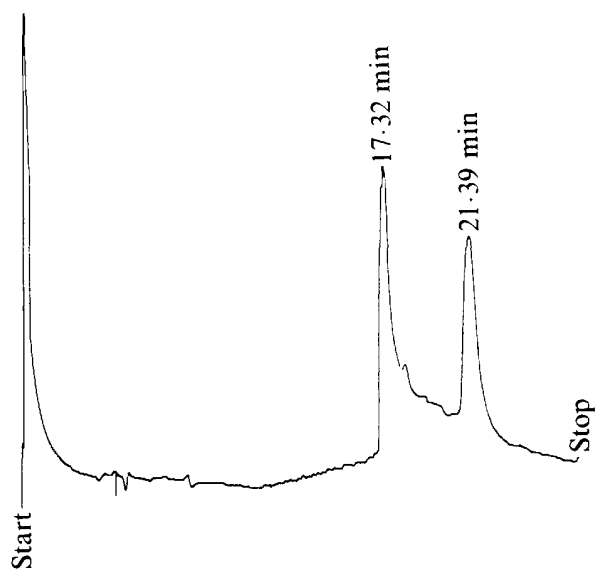

Fig. 1. Separation of lyase and endoglucanase. Material was applied to an LKB DEAE column and eluted with a complex gradient of increasing ionic concentration (programme ACB3) in 50 mM-HEPES pH 7.6. The eluate was monitored at $280 \mathrm{~nm}$.

\section{Table 1. Lyase action on different xanthans}

All results represent the mean of 6-10 duplicate estimations.

Source of xanthan

Lyase activity

[pmol TBA (mg protein) $)^{-1}$ per $\left.16 \mathrm{~h}\right]$

$X$. campestris pathovar:

campestris 646

phaseoli 1128

$27 \cdot 1$

phaseoli X45

$33 \cdot 0$

oryzae 61

oryzae 71

oryzae 79

oryzae 86

identified as lyase activity eluting at $17.3 \mathrm{~min}$ and endoglucanase at $21.4 \mathrm{~min}$ respectively in the case of the Bacillus material. Through repeated use of the FPLC column, enough lyase activity, free from endoglucanase, was obtained to perform tests on its specificity. Enzyme from the Corynebacterium species and from mixture $\mathrm{X} 23$ behaved similarly but yields were insufficient for extensive testing. Insufficient material was available for $M_{\mathrm{r}}$ determination by PAGE, but FPLC on a size-exclusion column (TSK $4000 \mathrm{PW}$ ) indicated a value in the range $30000-33000$. The lyase was free of all mannosidase activity. The $\mathrm{pH}$ optimum of the lyase was approximately $7 \cdot 25$ and all assays were performed at this $\mathrm{pH}$.

\section{Specificity of the lyases}

When tested against a range of different xanthan preparations, lyase activity as measured by release of TBA-positive material varied considerably (Table 1). Of particular interest was the finding that three preparations from strains of $X$. campestris pv. oryzae, 71,79 and 86 , which are not readily hydrolysed by 'xanthanases', yielded comparable amounts of TBA-positive material to the other xanthans. As it was anticipated that the presence or absence of acyl groups, pyruvate on the terminal $\beta$-mannosyl residue, and acetate on the internal $\alpha$-mannosyl residue, might affect lyase activity, xanthans with differing acyl substituents were also tested (Table 2). The results indicated that the lyase functions on either acylated or non-acylated polymers.

As the lyases were always found to be associated in cultures with endoglucanases, in their natural environment they might well function after preliminary degradation of the polysaccharides to soluble oligosaccharides. This aspect of specificity was examined by using a 
Table 2. Effect of acyl substituents on lyase activity

\begin{tabular}{lccc}
\multicolumn{1}{c}{$\begin{array}{c}\text { Acetate } \\
(\%)\end{array}$} & $\begin{array}{c}\text { Pyruvate } \\
(\%)\end{array}$ & $\begin{array}{c}\text { Lyase activity } \\
\text { (nmol TBA per 16 h) }\end{array}$ \\
$\begin{array}{l}\text { X. campestris pathovar: } \\
\text { campestris } 646\end{array}$ & $4 \cdot 5$ & $4 \cdot 4$ & $18 \cdot 2$ \\
gummisudans 2182 & $10 \cdot 0$ & $4 \cdot 7$ & $8 \cdot 2$ \\
phaseoli 556 & $1 \cdot 1$ & $6 \cdot 0$ & $16 \cdot 4$ \\
phaseoli 1128 & $7 \cdot 7$ & $1 \cdot 7$ & $16 \cdot 4$ \\
phaseoli 1128 DAC * & 0 & $1 \cdot 3$ & $4 \cdot 9$ \\
\multicolumn{2}{c}{ * This preparation was chemically deacetylated. }
\end{tabular}

Table 3. Effect of substrate size on lyase activity

\begin{tabular}{ccc}
\multicolumn{1}{c}{ DP } & No. of repeat units & TBA release $(\mathrm{nmol})$ \\
$5-15$ & $1-3$ & $3 \cdot 1$ \\
$25-35$ & $5-7$ & $6 \cdot 2$ \\
$40-55$ & $8-11$ & $5 \cdot 7$ \\
$70-90$ & $14-18$ & $5 \cdot 3$ \\
$>90$ & $>18$ & $4 \cdot 4$
\end{tabular}

series of oligosaccharides prepared by the action of fungal cellulases on unordered xanthans (Sutherland, 1982) (Table 3). Other possible substrates included modified xanthans. The Dglucuronosyl residues could be converted chemically to D-glucosyl residues, yielding a poorly soluble macromolecule. This was not a substrate for either the lyases or the endoglucanases. Neither were xanthans that had been modified through the addition of amine and hydroxyethyl groups to free hydroxyl residues, although these alterations did not totally inhibit endoglucanase action. Another source of possible substrates were $A$. xylinum strains forming polymers which are thought to show some resemblance to part of the xanthan structure (Tayama et al., 1986). No detectable TBA-positive material was found from any of the preparations tested, after prolonged exposure to the xanthan lyases.

\section{Nature of the products}

Although the addition of lyase free of endoglucanase to native xanthans cleaved terminal mannosyl residues with attendant increase in absorption at $235 \mathrm{~nm}$, such polymeric products were only produced in low yield and were not readily amenable to characterization. Instead, the oligosaccharides obtained by the action of lyase on material of DP $<20$, or by the combined action of lyase and endoglucanase on xanthans, were examined. Typically two to five products were found on preparative paper chromatography of the diffusible products following combined action of these enzymes on polymeric substrates. Two of the products were identifiable as Dmannose and acetylated mannose. Two oligosaccharides, designated $\mathrm{A} 22$ and $\mathrm{A} 21\left(R_{\mathrm{Glc}} 0.35\right.$ and 0.15 respectively; $R_{\text {Cellobiose }} 0.96$ and 0.41 ), were detected and purified. A further slowermoving oligosaccharide on paper chromatography (A20) had an $R_{\mathrm{Glc}}$ of 0.06 . All three oligosaccharides contained D-glucose, D-mannose and (unsaturated) uronic acid in the molar ratio $2: 1: 1$. The fastest-moving fragment, A22, also contained $1 \mathrm{~mol}$ of acetate. FAB and NMR spectroscopy confirmed the identity of A22 and A21 as tetrasaccharides of $M_{\mathrm{r}} 704$ and 662 respectively, with the structures indicated in Fig. 2. A22 was the acetylated version of A21. The third oligosaccharide, A20, was believed to be the corresponding octasaccharide and was also acetylated, but the acetyl content was non-stoichiometric, representing a molar ratio of about $0 \cdot 7$. Thus the octasaccharide fraction is probably a mixture of acetylated and non-acetylated material. Detailed studies on the oligosaccharide structures will be published elsewhere. The production of the two tetrasaccharides depended on the substrate xanthan used. No A22 was obtained when non-acetylated polysaccharide was the substrate. Some xanthans with possibly aberrant composition or structure yielded further oligosaccharides, the identity of which has not yet been fully established. 


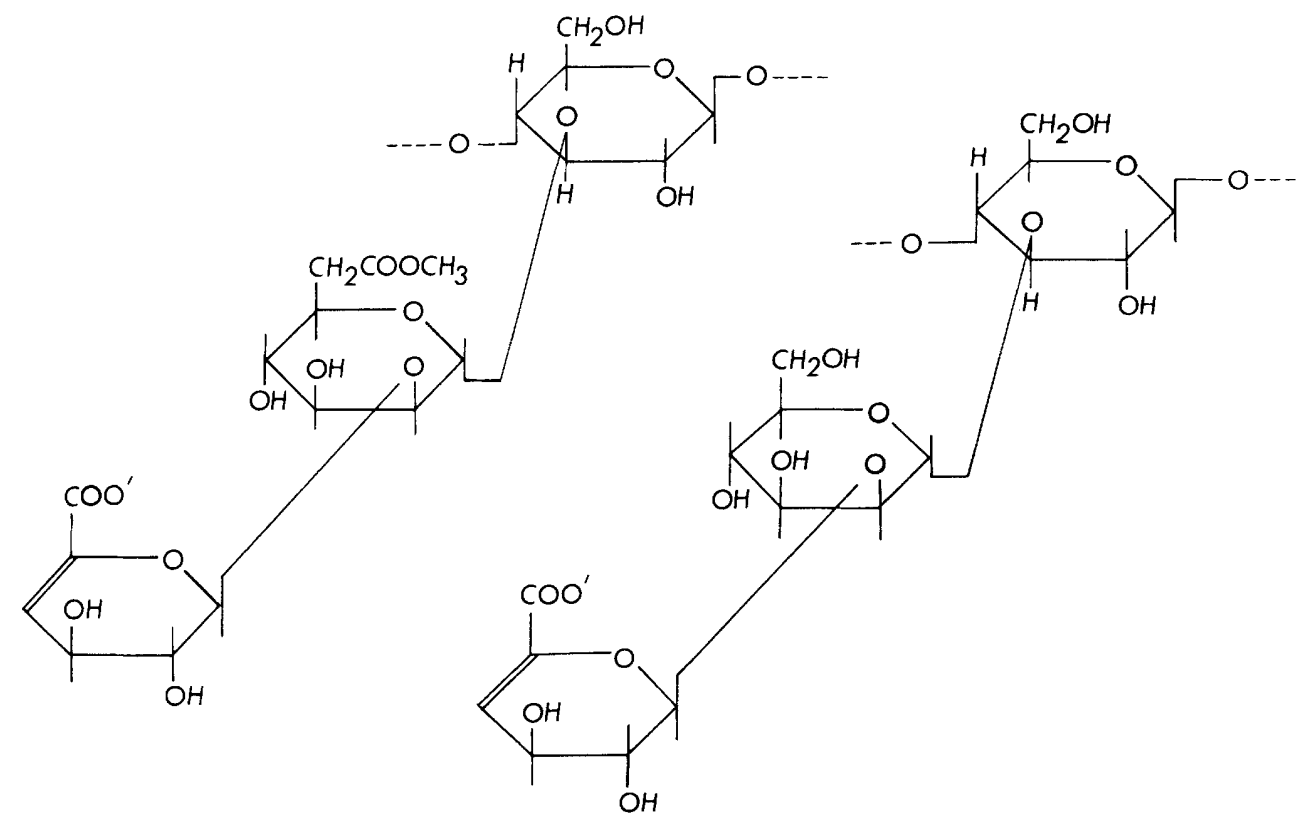

Fig. 2. Fragments resulting from the action of lyase on xanthan.

\section{DISCUSSION}

Enzymes degrading bacterial EPS, such as the uronic-acid-containing types of the different Klebsiella serotypes, have been obtained from heterologous bacteria or from bacteriophage. Most of these enzymes are hydrolytic in their mode of action, cleaving the backbone or main chain of the macromolecule. They have provided considerable structural information about polysaccharides composed of repeating units (e.g. Hisamatsu et al., 1980). No hydrolytic enzymes have yet been found for block copolymers such as bacterial or algal alginate, and less information is provided from the lyases acting on these substrates (Davidson et al., 1976, 1977). However, lyases for the EPS composed of repeating units have also been reported, including one of the first such enzymes characterized, that degrading the Streptococcus pneumoniae type VIII polysaccharide (Becker \& Pappenheimer, 1966). It is one of a number of lyases, 4,5transeliminases of bacterial or bacteriophage origin, now known to cleave the main chain of bacterial EPS (e.g. van Dam et al., 1985).

Enzyme systems degrading xanthan, the EPS from strains of Xanthomonas campestris, have been obtained from pure and mixed cultures. Most of these enzyme preparations have been mixtures of glucanases and glycosidases (Cadmus et al., 1982; Hou et al., 1986). The products of enzyme action have mainly been 'limit' oligosaccharides of relatively high $M_{\mathrm{r}}$, or monosaccharides and the cellulosic backbone of xanthan, although one report did suggest the possible action of a lyase (Lesley, 1961). Xanthan can also be degraded to a limited extent through the action of fungal cellulases from Aspergillus niger and Trichoderma viride on unordered polysaccharide in dilute solution (Sutherland, 1984). The enzymes only act slowly, yielding products of relatively high $M_{\mathrm{r}}$ together with oligosaccharides and some glucose. The action is inhibited by salts, which promote the ordered structure of the polysaccharide.

The only substrates identified for the xanthan lyases were EPS of the xanthan type or high- $M_{\mathrm{r}}$ oligosaccharides derived from them by main-chain cleavage, i.e. composed of the characteristic pentasaccharide repeating unit, with or without associated acyl groups. Certain Acetobacter xylinum polysaccharides have been reported to contain structural similarities to xanthan (Tayama et al., 1985, 1986), but no enzyme activity on these was detected. Activity was also absent if the xanthan molecule had been modified by various chemical procedures. The action of 
the lyase was apparently unaffected by the presence or absence of a 4,6 pyruvate ketal group on the terminal $\beta$-mannosyl side-chain residue of xanthan. This was surprising, as the ketal would be expected to alter the charge on that portion of the molecule and possibly also its configuration in solution. However, few xanthan preparations are fully pyruvylated (Jansson et al., 1975), therefore the enzyme has probably adapted to act on both ketalated and non-ketalated sidechains.

The xanthan lyases reported here are unusual in that they cleave the side-chain of a bacterial polysaccharide, whereas other lyases studied previously all appear to act on the main chain of their polysaccharide substrates. Despite this, a common feature of xanthan and other polysaccharides degraded by lyases is their site of action, a 4-linked uronosyl residue. In xanthan the actual site of attack is a $\beta$-D-mannosyl 1,4- $\beta$-D-glucuronosyl side-chain terminus. The enzymes, unlike the endoglucanases with which they are associated, only appear to act on xanthans and provide useful information on the fine structure of these widely used bacterial polysaccharides.

The author is grateful to Dr A. J. Clarke-Sturman, Sittingbourne, and Dr H. Parolis, Grahamstown, for the FAB and NMR spectroscopy and to Dr E. Weng, Trondheim, and Professor A. Misaki, Osaka, for the gift of polysaccharides.

\section{REFERENCES}

Becker, G. E. \& Pappenheimer, G. M. (1966). Lyase activity of inducible S8-depolymerases from Bacillus palustris. Biochimica et biophysica acta 121, 343-348.

BOYD, J. \& TURVEY, J. R. (1977). Isolation of a poly- $\alpha$ L-guluronate lyase from Klebsiella aerogenes. Carbohydrate Research 57, 163-171.

Bradshaw, I. J., Nisbet, B. A., KerR, M. H. \& SUTHERLAND, I. W. (1983). Modified xanthan - its preparation and viscosity. Carbohydrate Polymers 3 , 23-28.

Cadmus, M. C., Jackson, L. K., Burton, K. A., PlatTNer, R. D. \& Slodki, M. (1982). Biodegradation of xanthan gum by Bacillus species. Applied and Environmental Microbiology 44, 5-11.

Currie, A. J. \& Turvey, J. R. (1982). An enzyme method for the assay of D-mannuron C 5 epimerase activity. Carbohydrate Research 107, 156-159.

van Dam, J. E. G., van Halbeek, H., Kamerling, J. P., Vliegenhart, J. F. G., SNipPe, H., JANSZE, M. \& Willers, J. M. N. (1985). A bacteriophage-associated lyase acting on Klebsiella serotype 5 capsular polysaccharide. Carbohydrate Research 142 , 338-343.

Davidson, I. W., Sutherland, I. W. \& Lawson, C. J. (1976). Purification and properties of an alginate lyase from a marine bacterium. Biochemical Journal 159, 707-713.

Davidson, I. W., Lawson, C. J. \& Sutherland, I. W. (1977). An alginate lyase from Azotobacter vinelandii bacteriophage. Journal of General Microbiology 98 , 223-229.

Hisamatsu, M., Abe, J., Amemura, A. \& Harada, T. (1980). Structural elucidation on succinoglycan and related polysaccharides from Agrobacterium and Rhizobium by fragmentation with special $\beta$-D-glycanases and methylation analysis. Agricultural and Biological Chemistry 44, 1049-1055.

Holt, M. S. (1978). Production of exopolysaccharide by washed cell suspensions of Xanthomonas compestris. MPhil thesis, CNAA.

Hou, C. T., Barnabe, N. \& Greaney, K. (1986).
Purification and properties of a novel xanthan depolymerase from a salt-tolerant bacterial culture. Applied and Environmental Microbiology 52, 37-44.

Jansson, P.-E., KenNe, L. \& LindberG, B. (1975). Structure of the extracellular polysaccharide from Xanthomonas campestris. Carbohydrate Research 45, 275-282.

Kennedy, A. F. D. \& Sutherland, I. W. (1987). Analysis of bacterial exopolysaccharides. Biotechnology and Applied Biochemistry 9, 12-19.

LESLEY, S. M. (1961). Degradation of the polysaccharide of Xanthomonas phaseoli by an extracellular bacterial enzyme. Canadian Journal of Microbiology 7, 815-825.

Melton, L. D., Mindt, L., Rees, D. A. \& Sanderson, G. R. (1976). Covalent structure of the extracellular polysaccharide from Xanthomonas campestris: evidence from partial hydrolysis studies. Carbohydrate Research 46, 245-257.

Rinaudo, M. \& Milas, M. (1980). Enzymic hydrolysis of the bacterial polysaccharide xanthan by cellulase. International Journal of Biological Macromolecules 2, 45-48.

SUTHERland, I. W. (1982). An enzyme system hydrolysing the polysaccharides of Xanthomonas species. Journal of Applied Bacteriology 53, 385-393.

SUTHERLAND, I. W. (1984). Hydrolysis of unordered xanthan in solution by fungal cellulases. Carbohydrate Research 131, 93-104.

Tayama, K., Minakami, H., Entani, E., Fujiyama, S. \& MisaI, H. (1985). Structure of an acidic polysaccharide from Acetobacter sp. NBI 1022. Agricultural and Biological Chemistry 49, 959-966.

Tayama, K., Minakami, H., , Fujiyama, S., Misai, H. \& MiSAKI, A. (1986). Structure of an acidic polysaccharide elaborated by Acetobacter sp. 1005. Agricultural and Biological Chemistry 50, 1271-1278.

Weissbach, A. \& Hurwitz, J. (1958). The formation of 2-keto-3-deoxy-heptonic acid in extracts of Escherichia coli. Journal of Biological Chemistry 234, $705-709$. 